Cukurova Üniversitesi Mühendislik Mimarlık Fakültesi Dergisi, 30(1), 33-39 ss., Haziran 2015

Çukurova University Journal of the Faculty of Engineering and Architecture, 30(1), pp. 33-39, June 2015

\title{
Çapraz Akışlı Düz Borulu Saptırmalı Boru Demetinde Isı Transferi ve Basınç Kaybının Deneysel Olarak İncelenmesi
}

\author{
Alper YILMAZ ${ }^{* 1}$, Tuncay YILMAZ ${ }^{2}$ \\ ${ }^{1}$ Çukurova Üniversitesi, Otomotiv Mühendisliği Bölümü, Adana \\ ${ }^{2}$ Osmaniye Korkut Ata Üniversitesi, Makine Mühendisliği Bölümü, Osmaniye
}

Geliş tarihi: 28.01 .2015

Kabul tarihi: 25.06 .2015

\section{Özet}

Çapraz akışlı boru demetleri hem gaz-gaz hem de gaz-sıvı arasındaki 1sı transferinde çok kullanılan 1sı eşanjörleri arasında yer almaktadır. Bilhassa 1sı geri kazanımında en çok tercih edilen eşanjörler arasındadır. Kolay temizlenebilir olmaları dolayısıyla da kanatçıksız tipleri özellikle kirli akışkanlar için öncelik verilen eşanjör tipidir. Bu tip eşanjörlerde hacimsel 1sı transferinin büyük olması önemli bir husustur. Bunun için de kullanılan boru çaplarının mümkün olduğunca küçük olması arzu edilir.

Bu çalışmada, bu tür bir eşanjör kü̧̧ük bir boru çapında saptırılmış olarak yerleştirilmiş borulardan meydana gelen boru dışında akan sıcak havadan, boru içinden akan soğuk suya isı transferinde çeşitli şartlarda incelenmiştir. Isı transferi yanında basınç kayıpları da ölçülmüştür. Deneysel sonuçlardan 1S1 transferi ve basınç kayıp katsayıları hesaplanmış ve literatürde verilen eşitliklerle karşılaştırılmıştır.

Anahtar Kelimeler: Isı eşanjörü, Boru demeti, Isı transferi, Basınç kaybı, Saptırmalı

\section{Experimental Investigation of Heat Transfer and Pressure Loss for a Cross-flow Staggered Plain Tube Bank}

\begin{abstract}
Cross-flow tube bank heat exchangers are among the most commonly used heat exchangers for gas-gas and gas-liquid heat transfer. They are especially used for heat recovery and unfinned types are preferred heat recovery from waste dirty flue gases due to their resistance to fouling. High rate of volumetric heat transfer is an important issue for these kinds of heat exchangers. Therefore, tube diameters should be selected as small as possible.

In this study, a small diameter staggered tube bank heat exchanger without fins is investigated under different conditions where heat is transferred from hot air flowing shell-side to cold water flowing inside the tubes. Not only transferred heat but also pressure losses are measured. From the measured values, heat transfer coefficients and pressure loss coefficients are calculated and compared with the values calculated according to the equations given in literature.
\end{abstract}

Keywords: Heat exchanger, Tube bank, Heat transfer, Pressure loss, Staggered

* Yazışmaların yapılacağı yazar: Alper YILMAZ, Ç.Ü. Mühendislik Mimarlık Fakültesi, Otomotiv Mühendisliği Bölümü, Adana. alpyil@cu.edu.tr 


\section{GİRIŞ}

Çapraz akışlı boru demeti 1sı eşanjörleri, 1sıtma, soğutma, iklimlendirme, tekstil ve otomotiv endüstrisinde çokça kullanılan ısı eşanjörleridir. Bunun başlica sebebi, bu eşanjörlerin basit ve etkin olmaları yanında temizleme kolaylı̆̆ı da sayılabilir. Bu sebeplerden dolayı da bu eşanjörler üzerine birçok çalışmalar yapılmıştır.

En önemli çalışmalardan biri Zukauskas [1] tarafından yapılmış olup, Nusselt sayısı ve basınç kayıp katsayısı diyagramlar vasıtasıyla verilmiştir. Diğer önemli bir çalışma, Gnielinski [2] tarafından yayımlanmış ve bu araştırmada Nusselt sayısı için tüm parametreleri de içeren eşitlikler verilmiştir. Boru demetinde basınç kayıplarının hesaplanması için de Gaddis [3] tarafından tüm parametreleri içeren eşitlikler çıkarılmıştır.

Khan ve ark. [4] diferansiyel denklemleri analitik olarak çözmüşler ve hem parallel hem de saptırılmış diziliş için bağıntılar türetmişlerdir. Wilson ve Bassiouny [5] ile Shaboury ve Ormiston [6] ise diferansiyel denklemleri nümerik olarak çözmüşler, Nusselt ve basınç kayıp katsayısını Reynolds ve boyutsuz boru aralıklarının fonksiyonu olarak göstermişlerdir.

$\mathrm{Bu}$ çalışmada, saptırmalı boru dizilişinde düz borulu boru demetlerinde 1sı transferi ve basınç kaybı için deneysel sonuçlar bulunmaktadır.

\section{DENEY DÜZENEĞi}

\subsection{Deney Düzeneğinin Şematik Görünümü}

Deney düzeneği şekil 1 ve 2 de şematik olarak gösterilmiştir. V vantilatörüyle dişarıdan emilen hava, atık hava ile çapraz akışlı levhalı bir 1sı eşanjörü olan E2 de ön isıtmaya tabi tutulmaktadır. $\mathrm{Bu}$ hava 1 sınmış su ile de bir miktar daha 1sıtılarak hava 1sitıcısı (HI)'nda istenen sicaklığa getirilerek deney eşanjörü (DE)'ne verilmektedir. Burada soğutma kulesinde soğutulmuş ve sabit bir sıcaklıkta tutulmak için su 1sıtıcısı (SI)'ndan geçirilen su havayı soğutmak için kullanılmaktadır. Buradan çıkan su DE deney eşanjörüne verilerek 1sitılmaktadır. Deney eşanjöründen çıkan hava, E2 eşanjöründe sıcaklığ1 düşürüldükten sonra atmosfere atılmaktadır. Deney eşanjöründe 1sıtılan su da sıcaklığı E1 eşanjöründe düşürülmekte ve sonra da soğutma kulesi (SK) de sıcaklığı tekrar düşürülerek, P pompası vasıtasıyla su isitıcısına gönderilmektedir.

\subsection{Deney Düzeneğinin Gerçek Durumu}

Deney düzeneği Şekil 1'de gösterilen şemaya uygun olarak kurulmuştur. Sistemin kurulumu tamamlanmış olup ölçümlerin alınmasına hazır hale getirilmiştir.

\subsection{Deney Eşanjörü}

Deney eşanjörü saptırılmış borular şeklinde olup, görünüm ve boyutları Şekil 2 ve 3'te gösterilmiştir.

$\mathrm{DE}=$ Deney eşanjörü

$\mathrm{D}=$ Hava damperi

D1=Temiz hava / sıcak su eşanjörü

$\mathrm{HF}=$ Hava filtresi

$\mathrm{D} 2=$ Atık hava / temiz hava eşanjörü

SDÖ $=$ Su debisi ölçer

$\mathrm{HI}=$ Hava 1siticis 1

$\mathrm{SO}=$ Sicaklık ölçer

$\mathrm{SI}=\mathrm{Su}$ 1siticisi

$\mathrm{BÖ}=$ Mutlak basınç ölçer

$\mathrm{SF}=\mathrm{Su}$ filtresi

$\mathrm{BFÖ}=$ Basınç farkı ölçer

$\mathrm{Va}=\mathrm{Vana}$

$\mathrm{V}=$ Vantilatör

$\mathrm{P}=$ Pompa

Sistemde tüm eşanjörler, hava ve su isıtıcıları ile soğutma kulesi giriş ve çıkış sıcaklıklarını belirlemek için PT100 sensörleri kullanılmaktadır. Eşanjörlerin giriş ve çıkışlarında basınç farkları ölçülecek duruma getirilmiştir. Şekil 1'de deney düzeneği akış şeması üzerinde ölçüm noktaları gösterilmiştir.

$\mathrm{Su}$ debisi debi değerine göre rotametre 1, rotametre 2 ve elektronik debi ölçer ile ölçülmüştür. Bunların kalibrasyon eğrileri çıkarılmış olup, Şekil 4-6'da gösterilmiştir. 


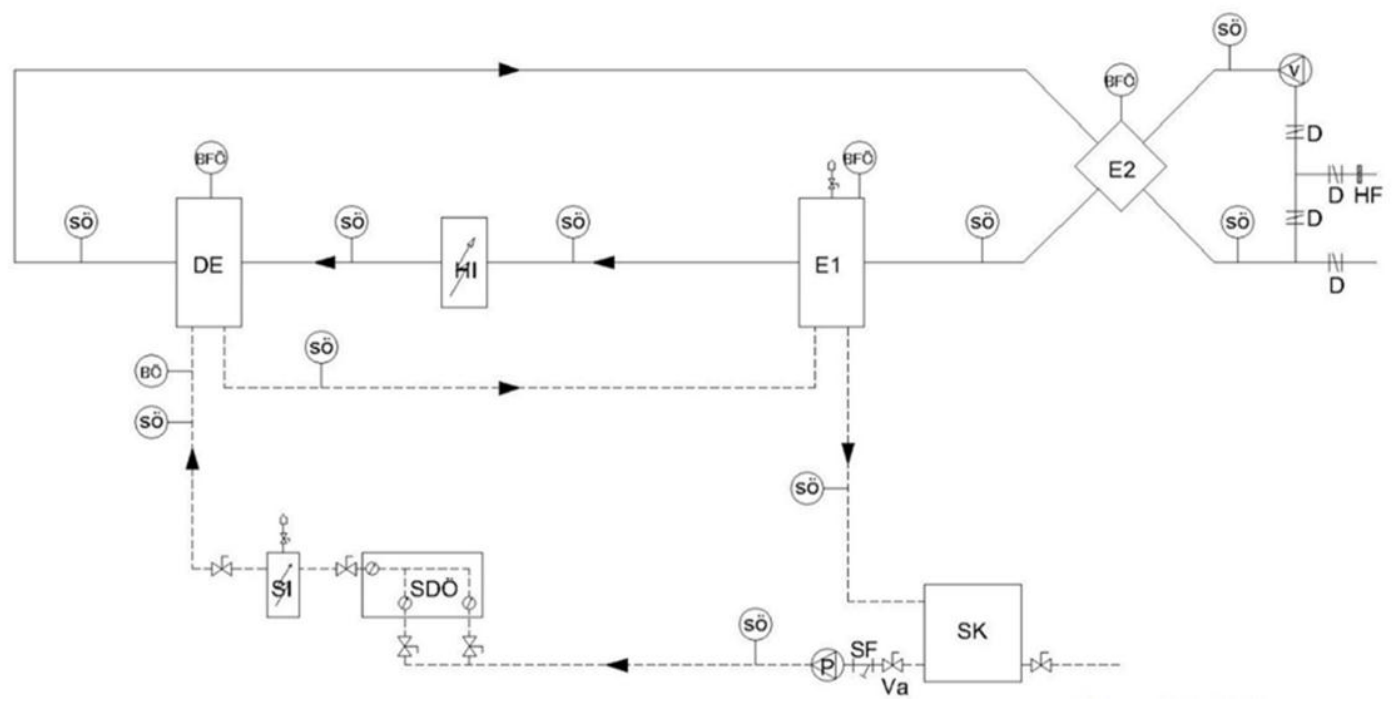

Şekil 1. Deney düzeneğinin şematik görünümü
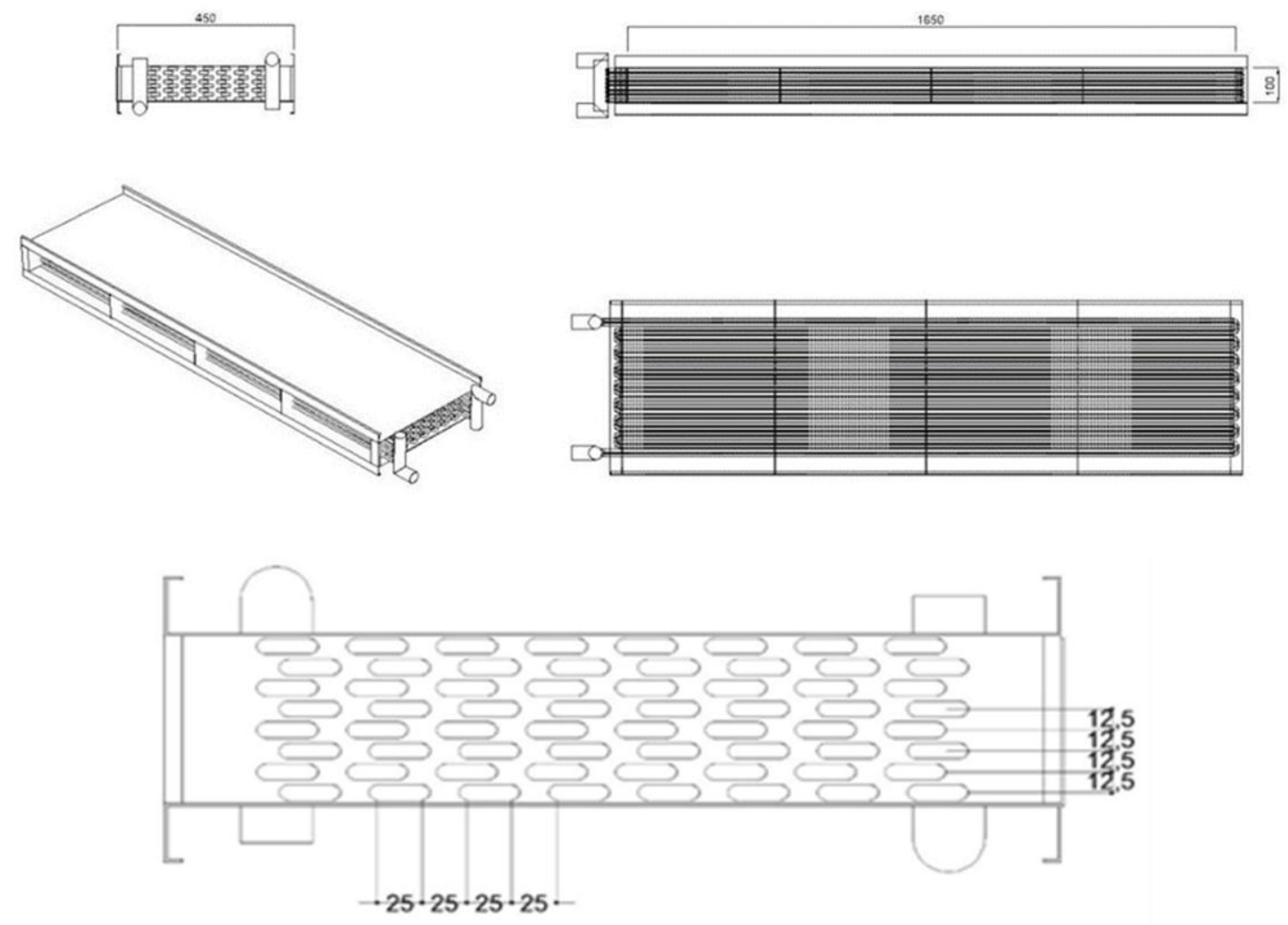

Şekil 2. Deney eşanjörünün (DE) görünümü ve boyutları 


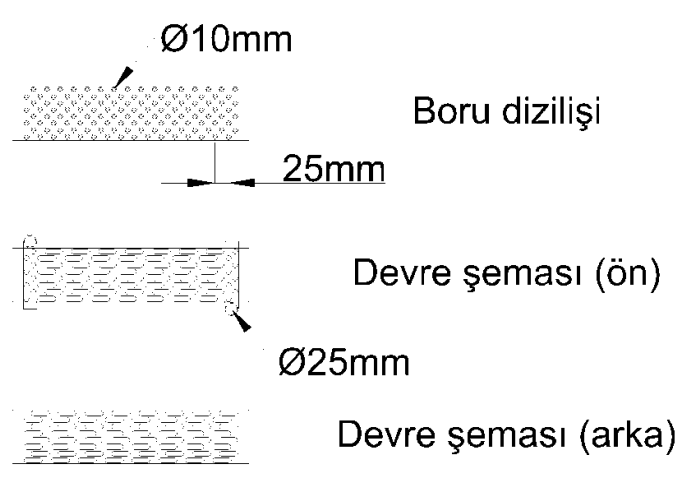

Şekil 3. Deney eşanjörünün (DE) boru dizilimi ve devre şeması

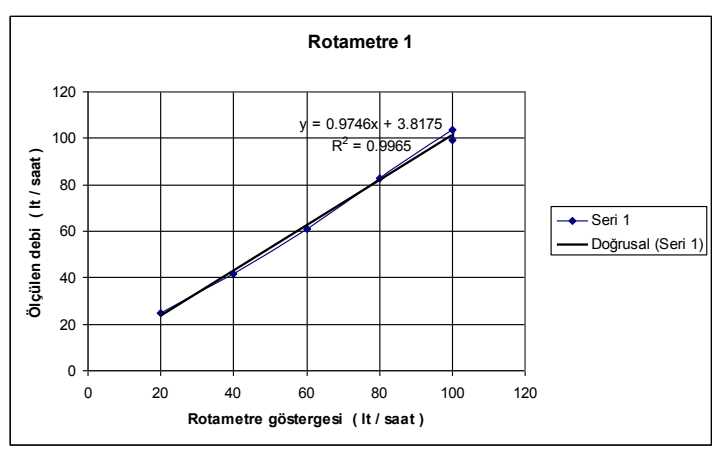

Şekil 4. Rotametre 1'in kalibrasyon eğrisi

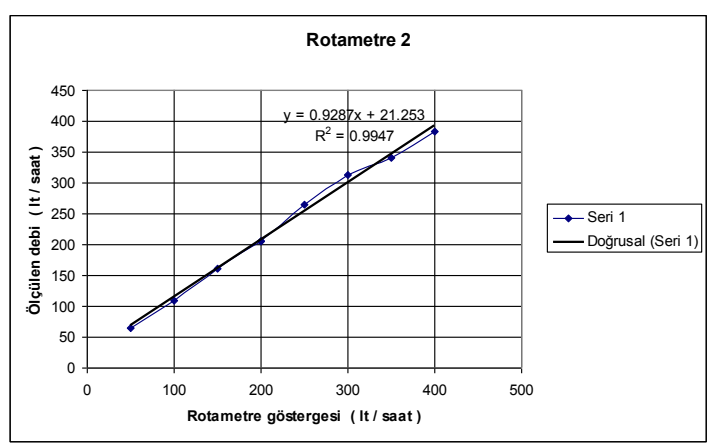

Şekil 5. Rotametre 2'nin kalibrasyon eğrisi

Hava debisi ölçümü ise pitot tüpü yardımıyla gerçekleştirilmiştir. Buradaki ve deney eşanjöründeki basınç farkları basınç fark sensörleri ve data logger üzerinden bilgisayara aktarılmıştır.

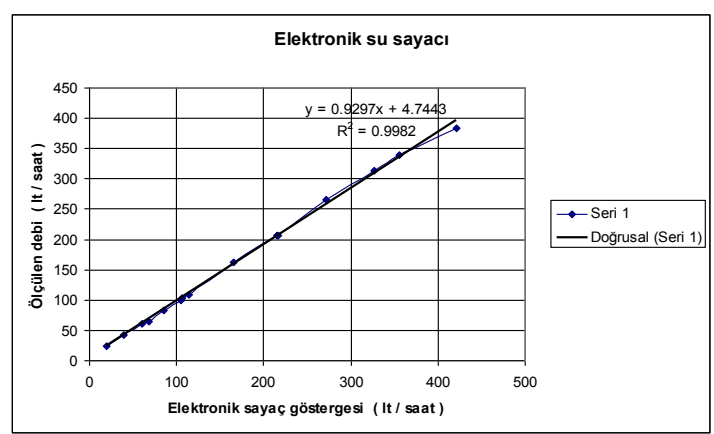

Şekil 6. Elektronik su debi ölçerin kalibrasyon eğrisi

\section{DENEY DÜZENEĞIINDE YAPILAN ÖLÇÜMLERIN DEG̈ERLENDİRILLESI}

Yapılan ölçümlerde alınan çıktılar kullanılarak 1s1 transferi katsayısı $h$, birim hacimde transfer edilen $1 \mathrm{~s} 1 \quad \dot{q}_{V}$ ve basınç kayıp katsayısı $f$ aşağıdaki eşitlikler kullanılarak hesaplanmıştır.

$h=\frac{\dot{Q}}{F \Delta T_{m}}$

$\dot{q}_{V}=\frac{\dot{Q}}{V \Delta T_{m}}$

$f=\frac{\Delta P}{\rho u^{2} / 2}$

Yukarıdaki eşitliklerde $\dot{Q}$ transfer edilen 1sıyı, $\Delta P$ eşanjör basınç kaybını, $u$ eşanjöre hava giriş hızını, $\rho$ havanın yoğunluğunu, $V$ ve $F$ eşanjör hacmi ve yüzey alanına, $\Delta T_{m}$ eşanjör logaritmik ortalama sıcaklık farkını göstermektedir. Hız ise havanın kütlesel debisi ( $\dot{M}$ )'nden faydalanılarak ,

$u=\frac{\dot{M}}{\rho A}$ 
şeklinde hesaplanmıştır. Yukarıdaki eşitlikteki $A$ borusuz eşanjörün kesit alanıdır.

Deneysel değerleri literatürdeki deneylerle karşılaştırmak için Nusselt sayısı ( $N u$ ), Reynolds sayısı ( Re) ve basınç kayıp katsayısı $(\lambda)$ aşağıdaki gibi tarif edilmiştir.

$$
\begin{aligned}
& N u=\frac{h d}{k} \\
& \operatorname{Re}=\frac{u_{\max } d}{v} \\
& \lambda=\frac{\Delta P}{N_{L} \frac{\rho u_{\max }^{2}}{2}}
\end{aligned}
$$

Burada $N_{L}$ akış yönündeki boru sayısıdır. $u_{\max }$ da boru demetindeki en yüksek hava hızıdır. Boyutsuz eşitliklerde ayrıca,

$$
\begin{aligned}
& s_{T}^{*}=\frac{s_{T}}{d} \\
& s_{L}^{*}=\frac{s_{L}}{d}
\end{aligned}
$$

tarifleri kullanılmaktadır. Deney eşanjöründe ilgili değerler aşağıda verilmiştir.

$$
s_{T}^{*}=2,5 \quad ; \quad s_{L}^{*}=1,25
$$

\section{SONUÇLAR}

Şekil 7'da DE'ndeki $h$ 1sı transferi katsayısının eşanjör hava giriş hızı ile değişimi verilmiştir. Değerlerin bir kısmı yüksek 1sı gücünde, bir kısmı da düşük 1 s1 gücünde elde edilmiştir. $\mathrm{Bu}$ diyagramdan $h$ nin beklendiği gibi $u$ ile arttığı görülmektedir. $h$ ile $u$ arasındaki bağıntı yaklaşık karekök $u$ ile orantılıdır ki bu da beklenen bir durumdur.

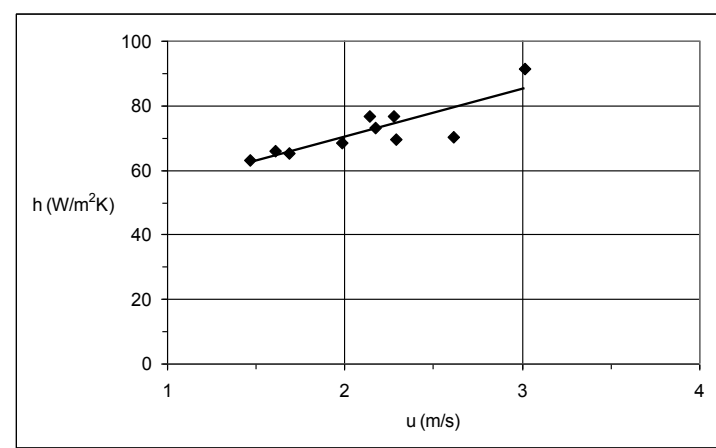

Şekil 7. DE'nde ısı transferi katsayısının hava hızı ile değişimi

Şekil 8'de özgül 1sı $\dot{q}_{V}$ 'nin hava hızı $u$ ile değişimi ayrıca verilmiştir.

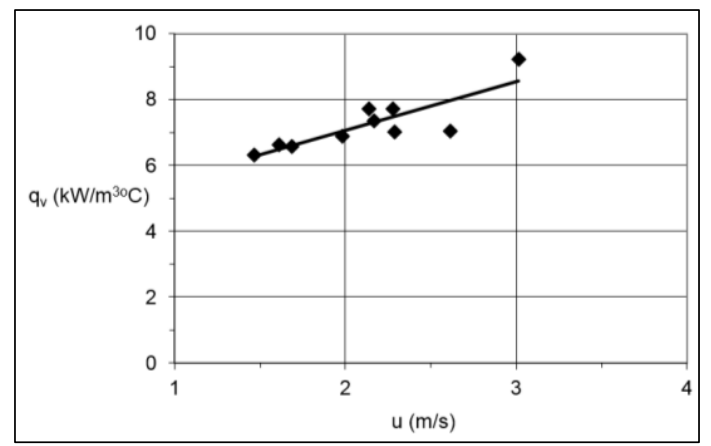

Şekil 8. DE'nde özgül ısı transferinin hava hızı ile değişimi

Şekil 9'da basınç kayıp katsayısı $f$ 'in $u$ ile değişimi gösterilmiştir. $f$ değerinin yaklaşık olarak sabit kabul edilebilir olduğu ve bu da akışın türbülanslı olduğunu göstermektedir.

Elde edilen sonuçlar literatürde verilen değerlerle karşılaştırmak için eşitlik (10) da verilenler dışında havanın fiziksel özellikleri için aşağıdaki değerler kullanılmıştır [7].

$T_{m}=75^{\circ} \mathrm{C} ; \rho=0,996 \mathrm{~kg} / \mathrm{m}^{3}$

$v=2,0810^{-5} \mathrm{~m}^{2} / \mathrm{s} ; \operatorname{Pr}=0,71$ 


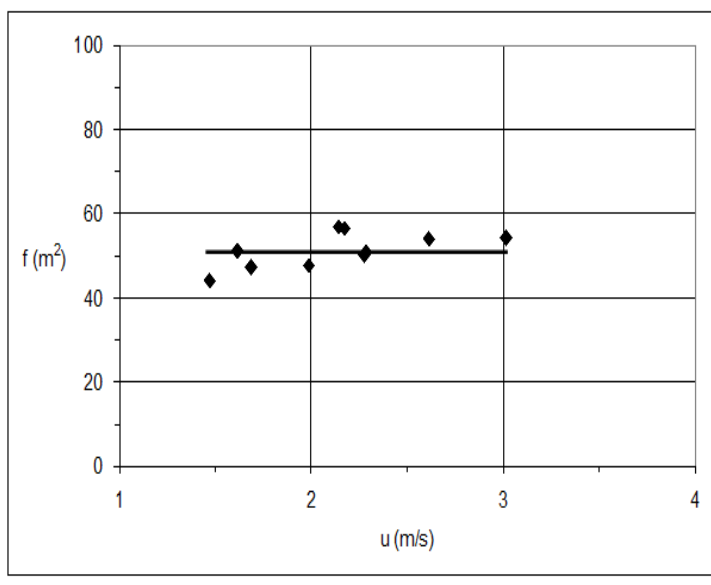

Şekil 9. DE'nde basınç kayıp katsayısı $f$ 'in hava hızı $u$ ile değişimi

$\mathrm{Bu}$ verilerle bu çalışmadaki geçerlilik sınırları içinde sayısı için Zukauskas eşitliği

$$
N u=0,355 \operatorname{Re}^{0,6}
$$

ve basınç kayıp katsayısı için de Gaddis eşitliği

$$
\lambda=\frac{22,09}{\operatorname{Re}}+\frac{3,139}{\operatorname{Re}^{0,25}}\left[1-\exp \left(-\frac{\mathrm{Re}+200}{1000}\right)\right]
$$

şeklinde yazılabilir. Gnielinski tarafından verilen eşitlikler yardımıyla hesaplar bir Fortran programı vasıtasıyla yapılmıştır. Basınç kayıpları Zukauskas tarafından bir diyagramla verildiğinden, değerler doğrudan bu diyagramdan alınarak kullanılmıştır.

Şekil 10'da bu çalışmada deneysel olarak elde edilen basınç kayıp katsayıları Gaddis [3] ve Zukauskas [1] tarafindan verilenlerle karşılaştırılmış olup, bu çalışmada elde edilen basınç kayıplarının daha büyük olduğu görülmektedir.

Şekil 11 'de de bu çalışmada deneysel olarak elde edilen değerleriyle Gnielinski [2] ve Zukauskas [1] tarafından verilenler karşılaștırılmıștır. Bu çalışmada elde edilen değerlerin daha küçük olduğu görülmektedir.

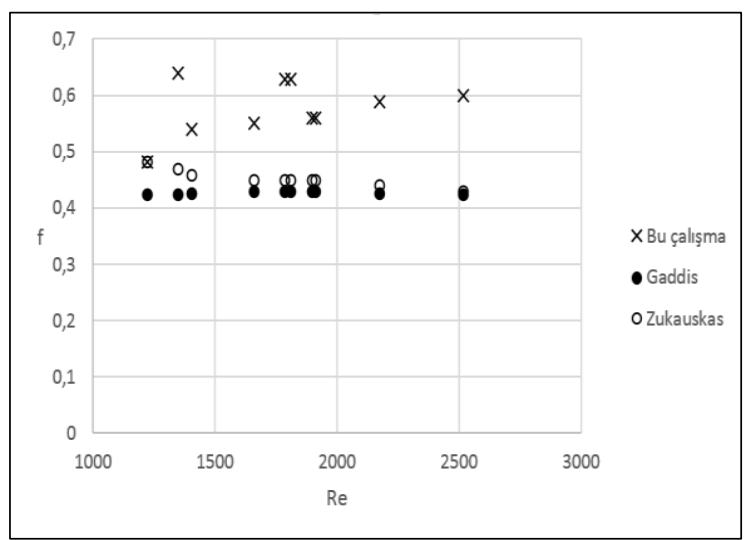

Şekil 10. Basınç kayıp katsayısının ( $f$ ) Reynolds sayısı ile değişimi

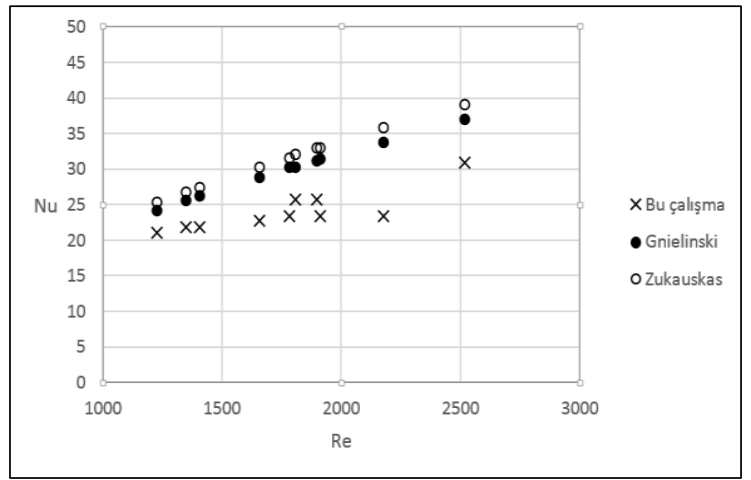

Şekil 11. $N u$ sayısının Reynolds sayısı ile değişimi

\section{TEŞEKKÜR}

$\mathrm{Bu}$ çalışma TEYDEB 7110772 nolu proje kapsamında hazırlanmış olup, Tübitak ve Barış Teknolojik Tesisat Sis. İnş. San. ve Tic. Ltd. Şirketi'ne katkılarından dolayı teşekkür ederiz.

\section{KAYNAKLAR}

1. Zukauskas A, Convective Heat Transfer in Cross Flow. In Handbook of Single Phase Convective Heat Transfer, ed. S. Kakac, R. K. Shah, W. Aung, pp. 6/1-6/45, Wiley, New York, 1987. 
2. Gnielinski V, Heat Transfer in Cross Flow Around Single Rows of Tubes and through Tube Bundles. In VDI Heat Atlas, ed. VDI, pp. 725-729, Springer Verlag, BerlinHeidelberg, 2010.

3. Gaddis ES, Pressure Drop of Tube Bundles in Cross Flow. In VDI Heat Atlas, ed. VDI, pp. 1076-1091, Springer Verlag, Berlin-Heidelberg, 2010.

4. Khan WA, Culham JR, Yovanovich MM, Convection Heat Transfer from Tube Banks in Cross Flow: Analytical Approach, International Journal of Heat and Mass Transfer, 49, 4831-4838, 2006.

5. Wilson AS, Bassiouny MK, Modeling of Heat Transfer for Flow Across Tube Banks, Chem. Eng. Processing, 39, 1-14, 2000.

6. El-Shaboury AMF, Ormiston SJ, Analysis of Laminar Forced Convection of Air Cross Flow in in-line Tube Banks with Non-square Arrangements. Numerical Heat Transfer, Part A, 48/2, 99-126, 2006.

7. Heat Atlas, VDI, Düsseldorf, 2010. 
